\title{
Currículos alternativos/oficiais: o(s) risco(s) do hibridismo*
}

\author{
Sandra Mara Corazza \\ Faculdade de Educação, Universidade Federal do Rio Grande do Sul
}

O número 21 da revista Contexto \& Educação, da Unijuí, de janeiro/março de 1991, trazia como temática geral a questão: "Experiências alternativas". Em seu Editorial, encontrava-se escrito: "As políticas educacionais não podem impor-se como se válidas para todos em toda parte; e as propostas pedagógicas só valem como propostas de sujeitos concretos em contextos determinados de vida e ação". Políticas e propostas "que devem ser tidas sempre como [...] alternativas", isto é, como "distintas e específicas", "não podendo elas decorrer de alguns princípios gerais, nem arvorar-se em panacéia para quaisquer situações" (p. 7).

Em 1995, em seu texto "Os novos mapas culturais e o lugar do currículo numa paisagem pós-moderna", Tomaz Tadeu da Silva argumentava que a nova

* Trabalho apresentado na sessão especial "Propostas curriculares: entre o oficial e o alternativo", promovida pelos Grupos de Trabalho Currículo, Educação Popular e Educação Fundamental, na $23^{\text {a }}$ Reunião Anual da ANPEd, realizada em Caxambu (MG), de 24 a 28 de setembro de 2000. direita, "triunfante em tantos países", colocara a educação e o currículo "no centro de reestruturação da sociedade ao longo de critérios baseados no funcionamento do mercado". O plano desta "aliança ou combinação de neoliberalismo (econômico) com neoconservadorismo (moral)" parecia, então, "muito claro", qual fosse: introduzir, na educação institucionalizada, "mecanismos de controle e regulação próprios da esfera da produção e do mercado", objetivando "produzir resultados educacionais", ajustados às "demandas e especificações empresariais".

Nesse cenário, era importante que os/as educadores/as começassem "a entender as novas configurações econômicas, políticas e sociais", por meio de "uma nova ótica", que focalizasse "as dinâmicas culturais em jogo na luta por hegemonia e predomínio político". A partir deste entendimento, sugeria Silva, os/as educadores/as poderiam começar sua luta pela consideração e afirmação de "discursos, narrativas e saberes [...] 'alternativos', que contassem outras histórias. Histórias que, por serem 'alternativas', minassem 'a inevitabilidade' e 'naturalidade' das narrativas dominantes" (p. 185-186). 
Passada quase uma década de contestação, conflitos e processos de negociação, vou argumentar, neste trabalho, que não conseguimos realizar nem uma coisa nem outra, ou seja, que não conseguimos legitimar nem consolidar políticas, currículos, propostas pedagógicas ou discursos "alternativos". Por um motivo bem simples: não que tenhamos fracassado, mas, porque, em função de muitos fatores (pertinentes à nossa condição histórica, profissional e subjetiva), perdemos o rumo, os limites e o diferencial, que nos permitiam distinguir o que era "oficial" do que era "alternativo".

\section{Tempos "fáceis" aqueles!}

Desde o final dos anos de 1960, vivíamos, no campo educacional crítico, uma "explosão" de teorias e práticas. Teorias da reprodução econômica. Nova sociologia da educação e do currículo. Oposição à política dos governos militares. Pedagogia libertadora e dos conteúdos. Teorias da resistência. Práticas de educação para a cidadania. Pesquisa-ação. Planejamento participativo. Movimento de reconceptualização do currículo. Educação, trabalho e democracia. Desvelamento da ideologia. Caça ao oculto do currículo.

Pedagogia radical, dialética, subversiva. Conhecimento escolar e poder. Lutas contra a educação capitalista excludente, e por acesso, permanência, sucesso no sistema escolar. Aliança de intelectuais orgânicos com sindicatos e movimentos sociais latino-americanos. Novas formas de agência, organização política e profissional. Pedagogia do oprimido. Educação popular.

Emergindo da articulação entre mudanças estruturais, políticas, demográficas e epistemológicas, toda essa "explosão" redundou em ruptura radical dos/as educadores/as de esquerda com o elitismo conservador e com o populismo reformista. Embora, por um lado, a luta pela democratização da sociedade e da educação fosse bem “difícil”, por um só ângulo (que é o que me interessa enfocar neste trabalho, a coisa toda parecia ser mais "fácil”. Fácil, porque nós, ainda, conseguíamos dividir o mundo, o sistema e nosso trabalho entre os "deles" e os "nossos".
Nossas ações e concepções funcionavam, então, pela via de um modelo espacial no sentido tópico, em cima/embaixo, dentro/fora, ou no sentido métrico, perto/longe... do poder dominante da burguesia, proprietária dos meios de produção. Existiam "eles", nossos inimigos capitalistas, claramente identificáveis, e "nós". "Eles" ocupavam o centro de poder, que formava e consolidava a ordem social dividida em classes antagônicas. Dentre outros aparelhos ideológicos de Estado, tal centro usava a escola para inculcar valores, condutas, modos de vida e conhecimentos a indivíduos destinados à proletarização. Contra o centro "deles", opúnhamos a nossa insubordinação de dominados/as críticos/as. Após o necessário suicídio de classe pequeno-burguesa, propúnhamos as "nossas" pedagogias, didáticas, metodologias, planejamentos, avaliações, utopias. Trabalhávamos pela escola conscientizadora que queríamos e pelos sujeitos contestadores que desejávamos formar.

Do centro de seu poder, "eles" propunham e implementavam o "currículo oficial": burocrático, ideologicamente tecnicista, hegemonicamente explorador, reprodutor de privilégios, produtor de desigualdades. Contra sua autoridade, produzíamos os "nossos currículos": alternativos, marginais, paralelos, nascidos das bases. Estes sim, currículos arduamente produzidos como populares, emancipatórios, revolucionários, socialistas. Currículos que davam sustentação às lutas políticas dos movimentos sociais, às identidades dos novos sujeitos da história e aos sonhos progressistas de uma futura sociedade democrática, mais justa e igualitária.

Essa diferenciação entre "eles" e "nós" (que hoje parece tão "fácil") se, de um lado, nos dotava de forças para produzir teorias e práticas alternativas ao poder central, de outro, não permitia que nos libertássemos da oposição “oficial x alternativo", pois, o máximo que conseguíamos, então, como educadoras/es críticas/os, era, simplesmente, inverter a valorização hierárquica dos termos binários. Ao invés de privilegiar o termo "oficial", o desvalorizávamos, como um "mal", elegendo o "alternativo". A este, atribuíamos o caráter de "verdade", de "bem", de "autenticidade". 
Entortávamos a tal "vara de Lenin" (como dizia alguém da época) para o lado de "nossos" currículos alternativos. "Legítimos" eram somente aqueles que vinham de baixo para cima, de fora para dentro, de longe para perto do poder, que queríamos fortalecer nas classes exploradas da sociedade. Com este movimento, o que não fazíamos era desconstruir a oposição “alternativo x oficial”. Por quê? Porque ainda podíamos, tínhamos condições de essencializar tanto um quanto o outro termo, e assim acreditar que existiam, em si mesmos, um currículo "oficial” e um ou vários “alternativos". Se esta era uma limitação de nossa lógica binária, ao menos ela impedia que fôssemos colocados/as, como hoje, diante do(s) risco(s) da dissolução de fronteiras.

\section{Tempos "difíceis" estes!}

Hoje, nestes tempos da nova ordem mundial, de capitalismo tardio em escala global, de neoliberalismo governamental e de soberania do mercado transnacional, não há mais um centro fixo: seja ele de poder, de produção e trabalho, de capital e cultura, de formação dos sujeitos. O conceito de "centro" é pensado como em modificação constante, como local não fixo, como um não-lugar. Não existe mais nenhuma dinâmica central, que explique todo o funcionamento da vida social. Não há um único eixo dos processos culturais, porque os eixos estão em toda parte, ou não existem. Não há explicações causais, radicadas nos processos econômicos, que justifiquem os resultados educacionais. Não há mais enraizamento, nem raízes, só rizomas, só redes de poder que movem o mundo. Redes do capital financeiro, de controle ao ar livre, do ciberespaço como o nosso atual laboratório metafísico.

Este é um tempo de reciclagens de ideologias, conhecimentos, comunicação. De novas tecnologias, hipertextos, tecnocultura, dispositivos interativos, ambientes telemáticos, luta de classes no silício. Tempo de reconfiguração e abolição de fronteiras entre ciência e ficção, público e privado, material e imaterial, humano e sobre-humano, natural e sobrenatural. De fomento de novas linhas divisórias, repetição de marginalizações ancestrais, mudanças em nossa ecologia física, cognitiva, afetiva, ética. De apogeu do localismo, da descentralização, da pura abstração codificada, da mestiçagem subjetiva. De simulação de mundos, simulacros de imagens, pastiches objetais, virtualização das realidades, simbiose entre máquina e organismo.

Neste tempo de "eus" saturados, monstros e ciborgues, manipulações genéticas, identidades clônicas do antigo humano moderno, Frankenstein não nos mete mais medo. Neste mundo pós-humano, também o Big Brother e o Panopticon não podem mais representar o poder. Este poder de agora é menos visível, mais insidioso, sem centro fixo. Nem por isto, é menos duro e implacável. Nem por isto, deixa de ser eficaz e eficiente em seus privilegiamentos, abjeções e forclusões. Este é o tempo que nos é próprio e comum. De nosso mundo pós-industrializado, que todas/ os ajudamos a produzir e cujo ápice de super-produção e hiper-consumo do Norte encontra correspondência na hiper-pauperização do Sul (cf. Gergen, 1992; Piscitelli, 1995; Sarup, 1995; Silva, 2000).

Porque somos sujeitos desta época e de nenhuma outra, não conseguimos experienciar mais a Educação e a Pedagogia do mesmo jeito que antes. Por isso, as praticamos, enquanto os novos seres híbridos que somos. Seres que, dentre outras características, possuem, em seus fazeres, pensares e dizeres, uma porção de currículo "oficial" e outra porção de currículo "alternativo". Ao perdermos os fatores distintivos, entre "oficial" e "alternativo", nossos currículos passam a ser representados pelo traço de união que liga, agora, as duas palavras.

Se isso que acabo de escrever merece o crédito de, minimamente, parecer plausível, o que este trabalho deverá fazer, daqui até o seu final, é demonstrar alguma manifestação desse sinal diacrítico, encarar esse risco à risca e avaliar os riscos de tal traçado.

\section{Dor do hífen: PCN-Constituinte Escolar/RS}

Por mais que isto me doa (e "dói”) realizarei o exercício analítico de buscar similaridades discursi- 
vas entre o Currículo Nacional, expresso nos PCNs, e o "Movimento Constituinte Escolar", movimento de "construção da Escola Democrática e Popular", que "visa a definição de princípios e diretrizes para a educação da rede pública estadual", do governo petista do Rio Grande do Sul (Estado/RS, 2000a, s.p.). Esta escolha da Constituinte Escolar do Rio Grande do Sul foi feita por sua proximidade geográfica, partidária e política. Embora, de meu ponto de vista, possa funcionar como "exemplar", não por ser um "modelo", mas por conter a possibilidade de representar outras propostas educacionais e curriculares que se propõem a ser de esquerda, democráticas, populares, participativas, cidadãs: numa palavra, "alternativas".

De modo intencional, vou enfatizar as similaridades encontradas no texto dessas duas propostas, não para negar as suas diferenças, pois elas existem. Mas para fornecer alguns elementos que nos permitam refletir sobre o que vem acontecendo com nossos currículos de educadores/as críticos/as que fazem oposição à política social, econômica e curricular do Governo Federal, e que acabam propondo quase a mesma Educação que a deste Governo. Além das dificuldades, bem concretas, relativas à formação e valorização dos/ as professores/as, ao financiamento e à gestão pública da Educação, ao marcar as semelhanças dos discursos, buscarei diagnosticar mais esta dificuldade que enfrentamos, hoje, no campo educacional: o amálgama entre o currículo oficial e os nossos, alternativos.

Em primeiro lugar, examino duas cartas de Apresentação aos/às professores/as, escritas, respectivamente, pela secretária de Educação do Rio Grande do Sul e pelo ministro da Educação e do Desporto do Brasil (cf. Estado/RS, 1999, p.4; Brasil, 1998b, p.5). Neste momento, identifico estas cartas; agrupo os seus parágrafos, sob títulos que deles extraí; e destaco, em itálico, aquilo que considerei suas similaridades discursivas (Ver Anexo II: 1 - Duas cartas).

Em seguida, apresento alguns fragmentos das propostas curriculares dos PCNs e da Constituinte Escolar do Rio Grande do Sul. Para organizá-los, selecionei enunciados dos dois currículos, reuni-os em temáticas sob um título comum e suprimi os seus da- dos de identificação. Procedi deste modo, pretendendo convidá-los/as para um "jogo". O jogo consiste em identificar qual proposta educacional é de quem. Qual é a do Governo FHC, e qual é a do Governo Olívio Dutra? (Ver Anexo II: 2 - Educação inclusiva; 3 Educação de qualidade; 4 - Democracia; 5 - Cidadania; 6 - Participação; 7 - Movimentos sociais; 8 Pluralidade cultural; 9 - Direitos humanos, valores humanistas; 10 - O sujeito da educação; 11 - Construção do conhecimento; 12 - Recursos tecnológicos; 13 - Professores/as).

\section{Tudo errado? Arrisco}

Muitas objeções poderão ser levantadas contra este modo de análise. Eu não posso dar conta de todas, e nem quero, pois não é esta a minha tarefa. Indico apenas aquelas que, penso, poderão nos ajudar a elucidar melhor o trabalho realizado.

1. Pra não dizer que não vi diferenças. Embora sejam poucas as diferenças (ou eu não as procurei, por uma questão de "método"), no texto dos PCNs há referências aos "valores sociais do trabalho e da livre iniciativa". Aparece também a natureza econômica da educação e da cultura: "Em função de uma economia dependente, não se desenvolveu [na sociedade brasileira] uma cultura e um sistema educacional que pudessem fortalecer a economia, fazendo-a caminhar para a auto-suficiência" (Brasil, 1998b, p. 19). Ambos os tópicos não são encontrados no texto da Constituinte Escolar/RS.

Assim como não constam dos PCNs os seguintes "pressupostos" da Constituinte Escolar do Rio Grande do Sul: 1. "Radicalização da democracia como objetivo estratégico de um governo de esquerda, comprometido com os interesses da maioria (as classes populares) estimulando a co-gestão da esfera pública na direção da soberania e controle popular sobre o Estado."; 2. "Utopia como sonho impulsionador da educação e da escola que queremos e também do projeto de desenvolvimento socioeconômico sustentável, possível e necessário para a imensa maioria de marginalizados e explorados do sistema capitalista. A utopia 
enquanto força impulsionadora da sociedade que queremos construir" (Estado/RS, 2000a, s.p.).

2. 'As duas propostas são “oficiais”. Poderá ser objetado: ora, ela não pôde demonstrar nenhum "hífen", porque não examinou nenhuma proposta "alternativa". As duas propostas são oficiais, no sentido de "estatais", uma, do Estado-União, outra de um Estado-Unidade da Federação. Ambas ocorrem dentro de instituições que servem aos interesses do Estado. São constituídas por práticas da esfera pública que, numa sociedade globalizada, como a nossa, não têm como se distinguir. Ambas as propostas dependem de financiamentos públicos e privados, pautados por critérios únicos de mercado. Ambas têm como legislação a cumprir a Lei de Diretrizes e Bases da Educação Nacional, que estabeleceu, em 1996, que a "educação, dever da família e do Estado, inspirada nos princípios de liberdade e nos ideais de solidariedade humana, tem por finalidade o pleno desenvolvimento do educando, seu preparo para o exercício da cidadania e sua qualificação para o trabalho". A Secretaria de Educação do Rio Grande do Sul, assim como todas as secretarias estaduais e municipais de Educação do Brasil, também está implicada no Plano Decenal de Educação para Todos (1993-2003), que formulou um conjunto de diretrizes políticas voltado para a recuperação da escola fundamental do país.

No plano internacional, ambas as propostas estão atreladas à UNESCO, ao UNICEF, ao PNUD, ao Banco Mundial. Subordinam-se ao compromisso assumido pelo Brasil, na Conferência Mundial de Educação para Todos, realizada na Tailândia, em 1990, que exigiu: "tornar universal a educação fundamental e ampliar as oportunidades de aprendizagem para crianças, jovens e adultos". Ambas são signatárias da Declaração de Nova Delhi, assinada pelos nove países “em desenvolvimento" de maior contingente populacional do mundo, e que reconheceu "a educação como instrumento proeminente da promoção dos valores humanos universais, da qualidade dos recursos humanos e do respeito pela diversidade cultural" (Brasil, 1998b, p. 19).

Isso pode estar certo. $\mathrm{O}$ que ainda contraponho a esta objeção é que a política educacional do Rio Grande do Sul, embora estatal, propõe-se a ser "alternativa", no sentido de fazer oposição à política do MEC. A Constituinte Escolar do Rio Grande do Sul faz uma opção declarada pelas classes populares, como pôde ser constatado pelos "pressupostos" de "radicalização da democracia" e de "utopia". Então, como a Constituinte usa quase o mesmo discurso que o Currículo Nacional, com que antagoniza? O dos PCNs não integra a tradição neoliberal em políticas da Educação? Ou também se destina aos grupos explorados da sociedade brasileira? Ou também é de um "governo de esquerda, comprometido com os interesses da maioria"?

3. 'Semânticas diferentes de um mesmo vocabulário. Poderá ser dito: o que o currículo nacional concebe como "cidadania", "democracia”, "participação", "professor", "currículo", não é, de modo algum, a mesma coisa que um governo de esquerda concebe. Se os vocábulos são os mesmos, suas significações diferem. Então, nada daquela organização (temáticas, títulos, destaques) é válido.

A questão é que, sim, pode ser isto: conceitos concebidos de modos diferentes. O problema é que as palavras têm história e, por ela, são dotadas de significações que, se são fluidas e negociadas, também fixam determinada realidade, modos de ser, pensar e agir. As palavras constróem, controlam e regulam as coisas e os indivíduos de um modo específico, e não de outros. Nos "ditos" dos dois textos, encontrei uma dissipação da diferença. As mesmas palavras são enunciadas pelos dois governos. Então, pergunto: se são opositores políticos, um do outro, não deveriam ter, cada um, o seu próprio vocabulário?

4. ' Processos diferentes. Alguém poderá lembrar: Uma das críticas mais recorrentemente feitas aos PCNs referia-se à ausência de um processo democrático e participativo em sua elaboração, que ficou restrita a um grupo limitado de especialistas e consultores. Já no processo da Constituinte Escolar/RS, está havendo, desde abril de 1999, "um processo de ampla participação popular de todos os segmentos da comunidade escolar e representações da sociedade civil". Neste ano, a Constituinte Escolar do Rio Grande do Sul realizou 
o "Estudo da Realidade" e o "Resgate de Práticas Pedagógicas". Este " $2^{\circ}$ Momento" propiciou que "cada comunidade" refletisse "o seu fazer cotidiano e histórico" e visualizasse "os principais conflitos e dificuldades nele existentes". Foram escolhidos então "25 Temas", que se articularam a "4 Temáticas para serem aprofundados".

Em 2000, a Secretaria de Educação do Rio Grande do Sul implementou o " $3^{\circ}$ Momento da Constituinte Escolar", denominado "Aprofundamento das Temáticas". Nele, houve "a devolução da sistematização do $2^{\circ}$ Momento e discussão dos Temas e Temáticas", por meio do texto-base para as pré-conferências municipais/microrregionais da Educação (Estado/RS, 2000c). Tal documento é "fruto da sistematização do 'Aprofundamento [...]', realizado pelas escolas, passando por 31 Seminários Regionais de Sistematização nas Delegacias de Educação e na Secretaria da Educação/RS e por uma sistematização em nível estadual". Este texto buscou contemplar "o conjunto das elaborações e proposições da comunidade escolar em todo o Estado" e foi discutido nas pré-conferências municipais, microrregionais e regionais.

$\mathrm{O}$ "4 $4^{\circ}$ Momento da CE/RS" foi o de "Definição dos Princípios e Diretrizes", desenvolvido na "Conferência Estadual de Educação", realizada em Porto Alegre, de 24 a 26 de agosto. Conforme o seu Regimento, desta conferência participaram "integrantes da comunidade escolar (pais, alunos, professores e funcionários), dos movimentos popular e sindical, das instituições de ensino, dos órgãos públicos, das organizações não-governamentais, dos fóruns setoriais, demais segmentos da sociedade civil, autoridades, convidados oficiais e observadores" (Estado/RS, 2000b, p. 8).

Claro que, visivelmente, os processos de formulação dos PCNs e da CE/RS são diferenciados em termos de representação e de participação. Mas, por isto mesmo, ainda posso insistir um pouco mais ao redor do ponto que moveu este trabalho e problematizar: (não é, no mínimo, "estranho" que, mesmo vivendo processos de elaboração tão distintos, os resultados discursivos das duas propostas apresentem tantas similaridades?
5. Não disse nada do currículo efetivo. Poderá ser formulada uma quinta objeção: Ela trabalhou "apenas" com o discurso escrito dos dois currículos. Apenas com o currículo formal, manifesto, explícito, oficial, com aquele que é dito que se faz, ou que deve ser feito. Não pesquisou o currículo oculto, o real, em ação, o implícito, aquele que costuma estabelecer distâncias entre o pretendido pela burocracia educacional e o que ocorre nas escolas. Ela não desceu ao nível da prática curricular das salas de aula, nem foi às práticas coletivas da comunidade escolar do Rio Grande do Sul, que realiza a "democracia participativa" em seu Movimento Constituinte.

Desta vez, eu confirmarei: é isto mesmo. Fiz esta "opção de método", porque concebo "discurso", ao modo da teorização social e cultural contemporânea: como prática objetivadora e construcionista, disposta por técnicas de poder, modos de saber e efeitos de verdade. Entendi o discurso curricular como tendo função governamental, que inscreve formas calculadas de ação sobre as condutas e relações de cada indivíduo e da população, para atingir certos objetivos sociais e políticos. Um discurso vinculado a tecnologias de governo, que habilitam os indivíduos a viverem tipos particulares de experiências e a se tornarem determinados tipos de sujeitos. Trabalhei com tal discurso como um dispositivo da governamentalização (neo)liberal, que vem transformando o campo do currículo numa nova, abrangente e eficaz tática de governo do Estado, dos/as outros/as e de cada um/a (cf. Corazza, 2000).

6. Tudo errado. Por fim, um espírito mais "agudo" poderá afirmar: está tudo errado! Não é nada disso. Nunca foi. Só parece que é. Ela se enganou, redondamente. Eu só poderei retrucar: tudo bem. Apesar da ênfase categórica nas semelhanças das duas propostas curriculares, como toda pesquisa educacional, a que subsidiou esta analítica também está sujeita ao questionamento e à desconstrução. De qualquer modo, acredito que ela possa ser uma contribuição, dentre tantas possíveis, sobre sua temática e método de análise. E, se for este o caso, que possa ser útil para um debate que, diante do que descreveu, talvez se faça necessário. 


\section{$\mathrm{O}$ risco à risca}

Mesmo em face dessas objeções, e de outras que nem pude imaginar, prossigo argumentando que nossas propostas curriculares atuais não estão "entre" o oficial e o alternativo. Estão no meio, no traço de união, no hífen de ligação. Que elas são fusão, associação, combinação. Que nossos currículos "alternativos", produzidos em quase trinta anos de trabalho nas organizações não-governamentais, sindicatos, movimentos sociais, escolas, vilas, universidades, estão lá, presentes e encravados no Currículo Nacional. E que este, “oficial”, está também aqui, nos currículos que organizamos e implementamos, e que ensinamos a organizar e a implementar.

Quando a equipe "que coordenou a elaboração dos PCNs", comentou "algumas das restrições feitas a seu trabalho", disse que a Fundação Carlos Chagas, a serviço do MEC, analisou "propostas curriculares oficiais existentes em todos os Estados do Brasil, além de algumas municipais" e que encontrou "uma grande identidade entre vários currículos", a qual foi incorporada aos PCNs. Isto, conforme a equipe do MEC, refutaria a crítica de que o currículo nacional não acolheu nem refletiu "movimentos ou experiências", que já estavam "acontecendo na sociedade brasileira".

A equipe não se enganou. Quem, como nós, formadores de docentes para a educação fundamental, pode negar que, neste trabalho, durante a década de 1980 e boa parte da década de 1990, não adotava, "por influência de uma perspectiva social e política", uma "proposta curricular voltada para a formação da cidadania plena"? Ou, quem pode negar que educava as/os educadoras/es desde "uma proposta psicopedagógica", que considerava "o aluno como ser pensante" e defendia "a idéia de trabalhar com a criança, desde pequena", com o objetivo de que ela fosse "capaz de construir sua autonomia"? (como a equipe do MEC afirmou. As "bases psicologizantes e cognitivistas" dos PCNs não estavam também presentes em nossas aulas? Por isso, a equipe pôde afirmar que era "verdadeira a crítica" sobre tais bases, pois, acrescentava, se "o professor não buscar compreender a natureza e a caracte- rística do pensamento do seu aluno sobre os objetos de aprendizagem escolar, não poderá planejar uma atuação adequada" (cf. Sanchez, 1997). Quem, nas faculdades de educação, não acreditou ou ensinou isto algum dia?

Não partilho da posição que postula que fomos "nós", educadores/as críticos/as, quem elaboramos os "fundamentos psicopedagógicos, socioantropológicos e epistemológicos", presentes nos PCNs. Fundamentos, que nos foram expropriados. Que "elas/es" nos tiraram, apropriaram-se, assimilaram os resultados de nosso trabalho e acúmulos críticos. Também não é possível aceitar que foram "elas/es" que elaboraram e estabeleceram tais fundamentos no currículo oficial. Afinal, não podem tanto. Todos/as nós fizemos, mantivemos, perpetuamos. Este é o "horror" do hibridismo educacional e pedagógico, que nos constitui atualmente. Este é o nosso "horror" político: descobrir que aqueles currículos, que considerávamos "nossos", estão também "capitalizados", "globalizados", "neoliberalizados". Que eles dizem a mesma coisa que aqueles currículos contra os quais lutamos. Que, talvez, já tenha chegado o tempo em que a dissipação das diferenças nos leva a não saber mais quem somos, o que queremos, o que propomos. Em que a dispersão dos limites nos leva a não identificar mais pelo que educamos e estudamos, pesquisamos e escrevemos, lutamos e vivemos.

\section{Avaliar o traçado}

Para des-montar, des-fazer, dis-juntar o que está aí, representado pelo traço de união entre currículo alternativo - currículo oficial, penso que podemos avaliar, no sentido nietzscheano de "criar". Duvidar de pretensos valores educacionais em si. Questionar o absolutismo dos valores de toda tradição educacional crítica, que nos formou. Afirmar a relatividade de valores, tais como direitos humanos, democracia, cidadania, escolarização. Avaliar o valor de nossas ações e convicções, pautadas por estes valores. Suspeitar que a autonomia e a liberdade não têm valor por sua natureza, mas que receberam valor um dia, e que fomos 
nós as/os doadoras/es. Doadores/as que forneceram valor e sentido às palavras que estão tanto no currículo nacional quanto na Constituinte Escolar do Rio Grande do Sul; que foi nossa avaliação que atribuiu valor a esses valores, e que, portanto, ao pô-los em questão, poderemos propor novos princípios de avaliação.

Fazendo isto (por mais que doa, e "dói”), estaremos, primeiro, aceitando que estamos implicadas/os, sim, nesse risco/traço, e correndo os riscos do hibridismo político-educacional. Em segundo lugar, estaremos mais aptos/as para exercitar nossa força criativa e produzir currículos que ainda não existem, para apontar nossas flechas e anseios a outras linguagens e teorias, diferentes conceitos e perspectivas, outros personagens e planos de imanência, novos modos de fazer pesquisa, de realizar a formação docente, de praticar o currículo.

Ao exercer nossa vontade criadora, justamente naquilo que nos é mais difícil de superar, poderemos, quem sabe, inventar, mais uma vez, a diferença, então, desfazer o risco de ligação, que fez com que nossos currículos deixassem de ser não-oficiais. Para isto, importa perguntar se tudo o que vimos, até agora, nas propostas curriculares, é tudo o que pode ser visto, e se tudo o que dissemos é tudo o que pode ser dito. Fabricar outros óculos e outra linguagem para ver e dizer as coisas e as palavras de "nossos" currículos. Sabendo que, se o seu traçado chegou até aqui, assim, é porque, como tal, foi criado. Se foi criado assim, poderá ser traçado de outros modos.

SANDRA MARA CORAZZA é professora adjunta do Departamento de Ensino e Currículo e do programa de pós-graduação em educação, da Faculdade de Educação da Universidade Federal do Rio Grande do Sul. Pesquisadora na área temática de póscurrículo, diferença e subjetivação de infantis, realiza e orienta investigações que articulam as teorizações sociais e culturais contemporâneas com os estudos de currículo, principalmente a partir das filosofias da diferença. Recentemente, publicou História da infância sem fim, IJUI: Ed. Unijuí, 2000; e está no prelo O que quer um currículo? pesquisas pós-críticas em educação, Petrópolis, Vozes, 2001. E-mail: sandracorazza@uol.com.br

\section{Referências bibliográficas}

BRASIL. Secretaria de Educação Fundamental, (1997a). Parâmetros curriculares nacionais: apresentação dos temas transversais, ética ( $1^{\mathrm{a}}$ à $4^{\mathrm{a}}$ série). Brasília: MEC/SEF, v. 8.

BRASIL. Secretaria de Educação Fundamental, (1997b). Parâmetros curriculares nacionais: meio ambiente, saúde $\left(1^{\mathrm{a}}\right.$ à $4^{\mathrm{a}}$ série). Brasília: MEC/SEF, v. 9.

BRASIL. Secretaria de Educação Fundamental, (1997c). Parâmetros curriculares nacionais: pluralidade cultural, orientação sexual ( $1^{\mathrm{a}}$ à $4^{\mathrm{a}}$ série). Brasília: MEC/SEF, v. 10.

BRASIL. Secretaria de Educação Fundamental, (1998a). Parâmetros curriculares nacionais: terceiro e quarto ciclos: apresentação dos temas transversais ( $5^{\mathrm{a}}$ à $8^{\mathrm{a}}$ série). Brasília: MEC/SEF.

BRASIL. Secretaria de Educação Fundamental, (1998b). Parâmetros curriculares nacionais: terceiro e quarto ciclos do ensino fundamental: introdução aos parâmetros curriculares nacionais ( $5^{\mathrm{a}}$ à $8^{\mathrm{a}}$ série). Brasília: MEC/SEF.

BRASIL. Ministério da Educação e do Desporto. Secretaria de Educação Fundamental, (1998c). Referencial curricular nacional para a educação infantil. Brasília: MEC/SEF (Carta de Fernando Henrique Cardoso, Presidente da República).

CORAZZA, Sandra M., (2000). Governamentalidade moral do currículo brasileiro. Porto Alegre, PPGEDU-UFRGS. 17p. (Artigo integrante de Projeto de Pesquisa, desenvolvido com apoio da PROPESQ-UFRGS e FAPERGS.) Mimeografado.

ESTADO do Rio Grande do Sul. Secretaria da Educação, (1999). Seminário estadual de sistematização. Constituinte Escolar (a construção da escola democrática e popular. Atividade III, IV e V. Esteio/RS, dez. 5p. Mimeografado.

ESTADO do Rio Grande do Sul. Secretaria da Educação, (2000a). Caderno 4 da Constituinte Escolar. Sistematização do $2^{\circ}$ Momento (Estudo da realidade e resgate de práticas pedagógicas). Porto Alegre, abr. s.p.

ESTADO do Rio Grande do Sul. Secretaria de Estado da Educação, (2000b). Regimento da Conferência Estadual da Educação. Porto Alegre, jun. 16p.

ESTADO do Rio Grande do Sul. Secretaria de Estado da Educação, (2000c). Texto-base das pré-conferências municipais $e$ micro-regionais da Educação. Porto Alegre, jul. 22p. 
GERGEN, Kenneth J., (1992). El yo saturado: dilemas de la identidad en el mundo contemporáneo. Barcelona: Paidós.

PISCITELLI, A., (1995). Ciberculturas: en la era de las máquinas inteligentes. Buenos Aires: Paidós.

SANCHEZ, Ana., (1997). Os Parâmetros Curriculares Nacionais e as críticas apresentadas. Pátio, ano I, nº 0, p.13-18, fev./abr.

SARUP, Madan, (1995). Hogar, identidad y educación. In: Vários. Volver a pensar la educación: política, educación y sociedad.
Madri: Morata. p.262-280, v.1, Congreso Internacional de Didáctica.

SILVA, Tomaz T. da, (1995). Os novos mapas culturais e o lugar do currículo numa paisagem pós-moderna. In: SILVA, T. T. da, MOREIRA, A. F. (org.). Territórios contestados: o currículo e os novos mapas políticos e culturais. Petrópolis: Vozes. p. 184-202.

(2000). Pedagogia dos monstros: os prazeres e os perigos da confusão de fronteiras. Belo Horizonte: Autêntica. 


\section{ANEXO I}

\section{1 - Duas cartas}

\section{Importância do currículo}

“A Secretaria de Estado da Educação, através deste documento, propõe à comunidade educacional gaúcha o debate, o aprofundamento e a reflexão em torno de um tema de indiscutível importância para a educação brasileira e riograndense: o currículo escolar” (Estado/RS, 1999, p. 4).

"O papel fundamental da educação no desenvolvimento das pessoas e das sociedades amplia-se [...] e aponta para a necessidade de se construir uma escola voltada para a formação de cidadãos. [...] Tal demanda impõe uma revisão dos currículos, que orientam o trabalho cotidianamente realizado pelos professores e especialistas em educação do nosso país” (Brasil, 1998b, p. 5).

\section{Entrega do ponto de partida}

"Ao submeter, agora, à comunidade educacional gaúcha e, em especial, aos nossos educadores, o resultado desse trabalho, ressaltamos, por oportuno, ainda, a circunstância de ser ele, na verdade, um ponto de partida para que, juntos, possamos construir um novo tempo para a educação no Rio Grande do Sul” (Estado/RS, 1999, p. 4).

“[...] é com imensa satisfação que entregamos aos professores [...] os Parâmetros Curriculares Nacionais, com a intenção de ampliar e aprofundar um debate educacional que envolva escolas, pais, governos e sociedade e dê origem a uma transformação positiva no sistema educativo brasileiro" (Brasil, 1998b, p. 5).

\section{Esperanças}

"Espera-se que o mesmo se constitua num instrumento de encontro, a partir do qual, professores, alunos, especialistas possam construir, coletiva e democraticamente, a educação que queremos, e cuja consecução passa hoje, necessariamente, pelo estabelecimento de um Padrão Referencial de Currículo" (Estado-RS, 1999, p. 4).
"Esperamos que os Parâmetros sirvam de apoio às discussões e ao desenvolvimento do projeto educativo de sua escola, à reflexão sobre a prática pedagógica, ao planejamento de suas aulas, à análise e seleção de materiais didáticos e de recursos tecnológicos e, em especial, que possam contribuir para sua formação e atualização profissional" (Brasil, 1998b, p. 5).

\section{Processo de avanços}

"Na busca deste Padrão Referencial de Currículo, muitos passos foram dados. Dentre eles, destaca-se a proposta de Reconstrução Curricular [...]. Esta caminhada produziu avanços na prática pedagógica de muitos professores, avanços estes que se deseja estendidos a todas as escolas. Além disso, é de considerar as produções realizadas nos últimos anos, no que se refere a conteúdos mínimos, seja de âmbito estadual, municipal ou privado" (Estado/RS, 1999, p. 4).

"Os documentos apresentados são o resultado de um longo trabalho que contou com a participação de muitos educadores brasileiros e tem a marca de suas experiências e de seus estudos, permitindo assim que fossem produzidos no contexto das discussões pedagógicas atuais" (Brasil, 1998b, p. 5).

\section{Revisão periódica do todo}

"Enfatiza-se, ainda, que na formalização deste documento, esta Secretaria teve como propósito reunir, resgatar e recompor num todo, harmônico e objetivo, não só os passos de muitos que nos precederam nesta jornada, mas também os estudos e formulações pertinentes às áreas de educação e currículo produzidos por seu Departamento Pedagógico" (Estado/RS, 1999, p. 4).

"As críticas e sugestões apresentadas contribuíram para a elaboração da atual versão, que deverá ser revista periodicamente, com base no acompanhamento e na avaliação de sua implementação" (Brasil, 1998b, p. 5).

\section{Esforços do MEC}

"Salienta-se, também, o esforço do Ministério da Educação e do Desporto para o estabelecimento dos Parâme- 
tros Curriculares Nacionais, com o intuito de subsidiar todas as escolas brasileiras, no que se refere a um programa básico comum de conhecimentos, como a própria denominação caracteriza" (Estado/RS, 1999, p. 4).

"Inicialmente foram elaborados documentos, em versões preliminares, para serem analisados e debatidos por professores que atuam em diferentes graus de ensino, por especialistas da educação e de outras áreas, além de instituições governamentais e não governamentais" (Brasil, 1998b, p. 5).

\section{2 - Educação inclusiva}

"Até hoje é uma sociedade [...] marcada por relações sociais hierarquizadas e por privilégios que reproduzem um altíssimo nível de desigualdade, injustiça e exclusão social. Na medida em que boa parte da população [...] não tem acesso a condições de vida digna, encontra-se excluída da plena participação nas decisões que determinam os rumos da vida social [...]. É nesse sentido que se fala de ausência de cidadania, cidadania excludente ou regulada, [...] (Brasil, 1997a, p. 21).

"[que] a educação se posicione na linha de frente da luta contra as exclusões, contribuindo para a promoção e integração de todos os brasileiros, voltando-se à construção da cidadania, não como meta a ser atingida num futuro distante, mas como prática efetiva" (Brasil, 1998b, p. 21).

"[...] o aprofundamento do Capitalismo [...] e com o avanço e a concentração tecnológica, com a especulação financeira, a exploração e o desrespeito aos direitos, [...], levaram a uma situação de miserabilidade setores tão significativos da população, que o modelo de regulação social não mais sustenta e mantém a submissão do conjunto da população" (Estado/RS, 2000a, s.p.)

"Educação como um direito de todos os cidadãos e cidadãs, enfatizando principalmente a situação daqueles que, ao longo da história, tiveram este direito negado, não conseguindo sequer entrar na escola ou que foram dela excluídos" (Estado/RS, 2000c, p. 5).

\section{3 - Educação de qualidade}

"A educação de qualidade social, direito de todos e dever do Estado, passa pela democratização do acesso e garantia de permanência e aprendizagem, na Escola Pública, independente da faixa etária, etnia, gênero, opção sexual ou condição social" (Estado/RS, 2000c, p. 11).

"Essa escola deve garantir a qualidade social da educação, assegurando a aprendizagem para todos, [...] (Estado/RS, 1999, p. 2).

"[...], cabe ao Poder Público garantir ensino de qualidade para todos" (Estado/RS, 2000a, s.p.).

“[...] meta de qualidade orientará o objetivo de contribuir para tornar a instituição educacional um espaço dinâmico e vivo, no qual as crianças alcancem o desenvolvimento integral de suas personalidades, crescendo como cidadãos cujos direitos são reconhecidos e respeitados" (Brasil, 1998c, Carta).

"[...] uma educação básica voltada para a cidadania. Isso não se resolve apenas garantindo a oferta de vagas, mas sim oferecendo-se um ensino de qualidade, ministrado por professores capazes de incorporar ao seu trabalho os avanços das pesquisas nas diferentes áreas de conhecimentos e de estar atentos às dinâmicas sociais e suas implicações no âmbito escolar" (Brasil, 1998b, p. 9).

"[...] uma educação de qualidade, que garanta as aprendizagens essenciais para a formação de cidadãos autônomos, críticos e participativos" (Brasil, 1998b, p. 21).

\section{4 - Democracia}

“[...] a democracia é uma forma de sociabilidade que penetra em todos os espaços sociais” (Brasil, 1997a, p. 20).

“[É] responsabilidade de todos a construção e a ampliação da democracia no Brasil” (Brasil, 1997a, p. 23).

“[...] a Democracia em nível político e social [...] deve ser um regime político em que há condições efetivas de socialização do poder" (Estado/RS, 2000a, s.p.).

"[...] que tem na democratização da escola seu eixo central, do qual deriva o compromisso político com a viabilização de um intenso projeto participativo para concretizar um ensino de qualidade social, vinculado à realidade e articulado com o projeto de desenvolvimento para o Brasil" (Estado/RS, 2000a, s.p.).

"Democratizar o ensino significa [...] assumir a educação pública como um direito de todos os cidadãos e um dever do Estado" (Estado/RS, 2000a, s.p.). 
"Democratizar é construir participativamente um projeto de educação de Qualidade Social" [...] (Estado/RS, 2000a, s.p.).

\section{5 - Cidadania}

"Durante décadas, as camadas populares tiveram sua participação reduzida à eleição de representantes políticos [...]. Consolidou-se assim a Democracia Representativa, cujo exercício do poder é delegado a algumas pessoas eleitas, [...] entendemos que a ampliação e o aprofundamento da Democracia exigem que todos participem efetivamente das decisões tomadas para o conjunto da sociedade" (Estado/RS, 2000a, s.p.).

[Propõe-se] "a construção de uma escola voltada para o exercício pleno da cidadania em todos os níveis e modalidades de ensino" (Estado/RS, 1999, p. 2).

"O compromisso com a construção da cidadania [...], eixo vertebrador da educação escolar” (Brasil, 1997a, p. 15).

"Como princípio democrático, traz a noção de cidadania ativa, isto é, da complementaridade entre a representação política tradicional e a participação popular no espaço público [...]” (Brasil, 1997a, p. 22).

"[...] noção de cidadania ativa, que tem como ponto de partida a compreensão do cidadão como portador de direitos e deveres, mas que também o vê como criador de direitos participando na gestão pública” (Brasil, 1997a, p. 21).

"O exercício da cidadania, que pressupõe a participação política de todos na definição de rumos que serão assumidos [...], e que se expressa na escolha de representantes políticos e governantes, mas também na participação em movimentos sociais, no envolvimento com temas e questões [...] em todos os níveis da vida cotidiana [...]" (Brasil, 1998a, p. 21).

"O papel fundamental da educação no desenvolvimento das pessoas e das sociedades [...] aponta para a necessidade de se construir uma escola voltada para a formação de cidadãos" (Brasil, 1998b, p. 5).

“[...] plenitude da cidadania para todos” (Brasil, 1997c, p. 21).

"[...] o exercício da cidadania numa sociedade democrática" (Brasil, 1997a, p. 65).
"[...] necessidade de garantir a todos a mesma dignidade e possibilidade de exercício de cidadania" (Brasil, 1997b, p. 22).

\section{6 - Participação}

“[...] cidadão [...], criador de direitos, condição que lhe possibilita participar da gestão pública" (Brasil, 1997a, p. 21).

“[...] partilhar com os poderes públicos e diferentes grupos sociais, organizados ou não, a responsabilidade pelos destinos da vida coletiva” (Brasil, 1997a, p. 23).

"Participação. Como princípio democrático, traz a noção de cidadania ativa, [...]. É, nesse sentido, responsabilidade de todos a construção e a ampliação da democracia no Brasil" (Brasil, 1998a, p. 21).

"[...] compreender a cidadania como participação social e política, assim como exercício de direitos e deveres políticos, civis e sociais [...]" (Brasil, 1997a, p. 7).

“[...] mostrar a importância da participação da comunidade na escola, de forma que o conhecimento aprendido gere maior compreensão, integração e inserção no mundo; a prática escolar comprometida com a interdependência escola-sociedade tem como objetivo situar as pessoas como participantes da sociedade (cidadãos) desde o primeiro dia de sua escolaridade" (Brasil, 1998b, p. 10).

“As políticas públicas educacionais [...] devem ser construídas com a participação da comunidade escolar" (Estado/RS, 2000c, p. 11).

"Fortalecimento da participação da comunidade na escola e da escola na comunidade, qualificando a integração escola-família-sociedade" (Estado-RS, 2000c, p. 8).

"Construção de um processo participativo de tomada de decisões administrativas, financeiras e pedagógicas [...]" (Estado/RS, 2000c, p. 8).

"Escola como espaço coletivo de construção de direitos e deveres (ética, valores, cidadania, responsabilidade), de exercício de democracia participativa, diálogo, justiça e igualdade" (Estado-RS, 2000c, p. 8).

"Educação como processo participativo de construção e apropriação do conhecimento e de tecnologias para transformação da sociedade" (Estado/RS, 2000c, p. 13). 
"Participação da comunidade na construção de uma educação e escola comprometidas com o desenvolvimento social” (Estado/RS, 2000c, p. 13).

"Participação popular como método de gestão das políticas públicas na área de educação, estimulando e garantindo condições para a construção coletiva da educação que queremos" (Estado-RS, 2000a, s.p.).

\section{7 - Movimentos sociais}

“[...] novos sujeitos políticos se constróem, enquanto agentes de pressão por mudança: os sujeitos coletivos, que passam a buscar o direito de reivindicar direitos, que se propõem a construir uma sociedade que responda aos interesses dos trabalhadores. Esses sujeitos são os Movimentos Sociais Populares" (Estado/RS, 2000a, s.p.).

"A própria luta por Educação, por escolas, por exemplo, o exercício desse direito de reivindicar direitos, constrói nos sujeitos nova visão de sociedade, novas formas de relação entre si, uma cultura política onde os trabalhadores se identificam, efetivamente, enquanto sujeitos históricos" (Estado/RS, 2000a, s.p.).

"[...] a cidadania deve ser compreendida como produto de histórias sociais protagonizadas pelos grupos sociais, sendo, nesse processo, constituída por diferentes tipos de direitos e instituições" (Brasil, 1998a, p. 19).

"Novos atores, novos direitos, novas mediações e novas instituições redefinem o espaço das práticas cidadãs, propondo o desafio da superação da marcante desigualdade social e econômica da sociedade brasileira, com sua conseqüência de exclusão de grande parte da população na participação dos direitos e deveres" (Brasil, 1998a, p. 20).

"Igualdade de direitos [...]. Para tanto há que se considerar o princípio da eqüidade, isto é, que existem diferenças (étnicas, culturais, regionais, de gênero, etárias, religiosas, etc.) e desigualdades (socio-econômicas) que necessitam ser levadas em conta para que a igualdade seja efetivamente alcançada” (Brasil, 1997a, p. 22).

"Co-responsabilidade pela vida social. Implica partilhar com os poderes públicos e diferentes grupos sociais, organizados ou não, a responsabilidade pelos destinos da vida coletiva" (Brasil, 1997a, p. 23).
"A conquista de significativos direitos sociais, nas relações de trabalho, previdência social, saúde, educação e moradia, amplia a concepção restrita de cidadania. Os movimentos sociais revelam as tensões que expressam a desigualdade social e a luta pela crescente eqüidade na participação ou ampliação dos direitos, assim como da relação entre os direitos individuais e os coletivos e da relação entre os direitos civis, políticos, sociais e econômicos com os Direitos Humanos" (Brasil, 1998a, p. 20).

\section{8 - Pluralidade cultural}

“[...] conhecer e valorizar a pluralidade do patrimônio sociocultural brasileiro, bem como aspectos socioculturais de outros povos e nações, posicionando-se contra qualquer discriminação baseada em diferenças culturais, de classe social, de crenças, de sexo, de etnia ou outras características individuais e sociais" (Brasil, 1997a, p. 7).

“[...] aprender a viver com os outros, que consiste em desenvolver a compreensão do outro e a percepção das interdependências, na realização de projetos comuns, preparando-se para gerir conflitos, fortalecendo sua identidade e respeitando a dos outros, respeitando valores de pluralismo, de compreensão mútua e de busca da paz" (Brasil, 1998b, p. 17).

"Respeito à diversidade cultural, étnica, de gênero e opção sexual, religiosa e política” (Estado/RS, 2000c, p. 8).

"A educação de qualidade social, direito de todos e dever do Estado, passa pela democratização do acesso e garantia de permanência e aprendizagem, na Escola Pública, independente da faixa etária, etnia, gênero, opção sexual ou condição social” (Estado/RS, 2000c, p. 11).

\section{9 - Direitos humanos, valores humanistas}

"Educação como base do desenvolvimento social, que tem como centro o ser humano" (Estado/RS, 2000c, p. 13).

"Valorização da vida com qualidade social e condição digna de existência para todos" (Estado/RS, 2000c, p. 13).

"Educação fundada em valores humanistas (solidariedade, justiça social, honestidade, responsabilidade e respeito), como condição da construção social do conhecimento" (Estado/RS, 2000c, p. 9). 
"Dialogicidade como um princípio ético-existencial de um projeto humanista e solidário, respeitador das diferenças e da pluralidade de visões de mundo, porém crítico e propositivo perante as desigualdades e injustiças sociais" (Estado/RS, 2000a, s.p.).

"Nessa prática de luta por direitos, de organização e mobilização dos trabalhadores, encontramos uma nova forma de relação entre a Educação e a construção do ser humano" Estado/RS, 2000a, s.p.).

"Possibilita [...] que seja resgatado o papel de cada um enquanto sujeito do mundo que construímos a cada dia, e a partir do nosso dia-a-dia" (Estado/RS, 2000a, s.p.).

"[...] reafirmamos o nosso compromisso com o aprofundamento do caráter humanista da escola, [...]" (Estado/ RS, 2000a, s.p.).

"Dignidade da pessoa humana. Implica em respeito aos direitos humanos, repúdio à discriminação de qualquer tipo, acesso a condições de vida digna, respeito mútuo nas relações interpessoais, públicas e privadas" (Brasil, 1998a, p. 21).

“[...] adotando, no dia-a-dia, atitudes de solidariedade, cooperação e repúdio às injustiças, respeitando o outro e exigindo para si o mesmo respeito" (Brasil, 1997a, p. 5).

\section{0 - O sujeito da educação}

“[...] demanda uma educação de qualidade, que garanta as aprendizagens essenciais para a formação de cidadãos autônomos, críticos e participativos, capazes de atuar com competência, dignidade e responsabilidade na sociedade em que vivem e na qual esperam ver atendidas suas necessidades individuais, sociais, políticas e econômicas" (Brasil, 1998b, p. 21).

"Aprender a ser, para melhor desenvolver sua personalidade e poder agir com autonomia, expressando opiniões e assumindo as responsabilidades sociais" (Brasil, 1998b, p. 17).

"Posicionar-se de maneira crítica, responsável e construtiva nas diferentes situações sociais, utilizando o diálogo como forma de mediar conflitos e de tomar decisões coletivas" (Brasil, 1997a, p. 7).

"Educação como processo permanente de formação de sujeitos autônomos, com posição crítica frente às desigualdades e injustiças sociais" (Estado/RS, 2000c, p. 13).
"Educação libertadora, formadora de sujeitos críticos e transformadores da realidade na perspectiva da construção de uma sociedade mais justa" (Estado/RS, 2000c, p. 8).

"[...] formar sujeitos que façam da prática da justiça, da liberdade, do respeito humano, das relações fraternas entre homens e mulheres e da convivência harmônica com a natureza, o centro de suas preocupações" (Estado/RS, 2000a, s.p.).

"[que a escola] seja um espaço de práticas, de exercício e de conquista de direitos, de formação de sujeitos históricos, autônomos, críticos e criativos, cidadãos plenos, identificados com os valores éticos e voltados à construção de um projeto social solidário" (Estado/RS, 2000a, s.p.).

"Concebemos a educação como um processo de formação e desenvolvimento da pessoa, que interage individual e coletivamente, [...]" (Estado/RS, 2000a, s.p.).

\section{1 - Construção do conhecimento}

“[...] participação efetiva das camadas populares como sujeitos de um processo de produção de conhecimento e, ao mesmo tempo, de definições de políticas públicas" (Estado/RS, 2000a, s.p.).

"Conhecimento universal compreendido como um direito de todos, construído coletivamente como processo de desvelamento, apreensão e transformação da realidade e mediado pelo contexto histórico-social" (Estado/RS, 2000c, p. 9).

"Construção do conhecimento comprometido com a transformação social, referenciado na realidade histórica, em interação com os diferentes saberes e valorização da cultura popular" (Estado-RS, 2000c, p. 9).

"Prática educativa democrática, participativa e dialógica como pressuposto do processo de construção social do conhecimento" (Estado/RS, 2000c, p. 9).

"Questionar a realidade formulando-se problemas e tratando de resolvê-los, utilizando para isso o pensamento lógico, a criatividade, a intuição, a capacidade de análise crítica, selecionando procedimentos e verificando sua adequação" (Brasil, 1997a, p. 8).

“ O compromisso com a construção da cidadania pede necessariamente uma prática educacional voltada para a compreensão da realidade social e dos direitos e responsa- 
bilidades em relação à vida pessoal, coletiva e ambiental" (Brasil, 1997a, p. 15).

"Aprender a conhecer, que supõe saber selecionar, acessar e integrar os elementos de uma cultura geral, [...], com o trabalho em profundidade de alguns assuntos, com espírito investigativo e visão crítica [...]" (Brasil, 1998b, p. 17).

\section{2 - Recursos tecnológicos}

“[...] apontar a necessidade do desenvolvimento de trabalhos que contemplem o uso das tecnologias da comunicação e da informação, para que todos, alunos e professores, possam delas se apropriar e participar, bem como criticá-las e/ou delas usufruir” (Brasil, 1998b, p. 11).

“[...] saber utilizar diferentes fontes de informação e recursos tecnológicos para adquirir e construir conhecimentos" (Brasil, 1997a, p. 8).

"O acesso às tecnologias [...] deve possibilitar a qualificação e inclusão social” (Estado-RS, 2000c, p. 11).

"Políticas públicas que garantam recursos tecnológicos, humanos e financeiros para o enriquecimento e qualificação do processo ensino-aprendizagem" (Estado/RS, 2000c, p. 11).

"Educação como processo participativo de construção e apropriação do conhecimento e de tecnologias para transformação da sociedade" (Estado/RS, 2000c, p. 13).

\section{3 - Professores/as}

“[...] é fundamental a valorização profissional dos trabalhadores em educação, o que implica [...] em política de formação e qualificação, ingresso exclusivamente por concurso público e garantia de condições dignas de trabalho, remuneração e carreira" (Estado/RS, 2000a, s.p.).

“A construção do conhecimento como processo coletivo e constante pressupõe a formação permanente dos/as trabalhadores/as em educação" (Estado/RS, 2000c, p. 9).

"Qualificação e formação de trabalhadores em educação para o atendimento às diversidades, democratizando o acesso à educação" (Estado/RS, 2000c, p. 11).

“[...] valorizar os trabalhos dos docentes como produtores, articuladores, planejadores das práticas educativas e como mediadores do conhecimento socialmente produzido; destacar a importância de que os docentes possam atuar com a diversidade existente entre os alunos e com seus conhecimentos prévios, como fonte de aprendizagem de convívio social e como meio para a aprendizagem de conteúdos específicos" (Brasil, 1998b, p. 11).

"Para desenvolver sua prática os professores precisam [...] desenvolver-se como profissionais e como sujeitos críticos na realidade em que estão, isto é, precisam poder situar-se como educadores e cidadãos, e, como tais, participantes do processo de construção da cidadania, de reconhecimento de seus direitos e deveres, de valorização profissional" (Brasil, 1997a, p. 52).

"Para o professor a escola [...] é lugar de possibilidade de construção de relações de autonomia, de criação e recriação de seu próprio trabalho, de reconhecimento de si, que possibilita redefinir sua relação com a instituição, com o Estado, com os alunos, suas famílias e comunidades" (Brasil, 1997a, p. 53). 
The appropriations of Pierre Bourdieu's work in the brazilian educational field

Based on research carried out in 20 specialised educational periodicals, published between 1971 and 2000, the present text analyses the forms of appropriation from Pierre Bourdieu's work in the field of Brazilian education. The set of 355 articles published in those periodicals that make reference to the sociologist constitutes the basic corpus for the analysis of the peculiarities of the Brazilian interpretations of this author.

Marcus Vinicius da Cunha

John Dewey e o pensamento educacional brasileiro: a centralidade da noção de movimento

$\mathrm{O}$ trabalho analisa artigos publicados em periódicos educacionais brasileiros entre 1930 e 1960, cujos temas são educação, democracia, filosofia, ciência e verdade, entre outros, desenvolvidos segundo concepções de Dewey. Em todos, ocupam posição central as noções de mudança e transformação, em oposição a estabilidade, fixidez e permanência. O objetivo é mostrar a relevância da noção de mundo em movimento, tanto para os brasileiros quanto para Dewey.

John Dewey and the brazilian educational thinking: the main position of the concept of change This paper analyses some articles published by educational journals in Brazil between 1930 and 1960, whose subjects are education, democracy, philosophy, science, truth and others, developed according to Dewey's ideas. In all of them, the main concept is the transformation of things, in opposition to steady. The central intent is to show the change of world like a key concept to the brazilian authors, as such as to Dewey.

\section{Sandra Mara Corazza}

Currículos alternativos/oficiais: o(s) risco(s) do hibridismo

$\mathrm{O}$ artigo enfatiza similaridades discursivas entre os PCNs do Ministério da Educação do Brasil, tidos como currículo oficial, e o Movimento Constituinte Escolar do governo petista do Rio Grande do Sul, proposto como currículo alternativo. Reflete sobre o que vem acontecendo com nossos currículos alternativos críticos, que acabam propondo quase a mesma educação que a do Governo Federal. Argumenta que, em função desse hibridismo, precisamos desfazer o risco de ligação, produzir e praticar currículos que ainda não existem, inventar mais uma vez a diferença.

\section{Alternative-official curricula: the} risk(s) of hybridism

The article stresses the discursive similarities between the National Curricula Parameters (PCN) established by the Brazilian Ministry of Education, considered the official curriculum, and the School Assembly Movement inspired by the Workers' Party state government in Rio Grande do Sul, proposed as an alternative curriculum. It discusses what has been happening with our critical alternative curricula which end up proposing almost the same education as that of the Federal Government. It forwards the argument that, as a consequence of this hybridism, we need to dispel the ambiguity, by producing and putting into practice curricula which do not yet exist and to invent once more the difference.

Reinaldo Matias Fleuri

Entre o oficial e o alternativo em propostas curriculares: para além do hibridismo

$\mathrm{O}$ texto discute a relação entre o oficial e o alternativo no discurso da Constituinte Escolar (1999-2000), pro- movida pelo governo do estado do Rio Grande do Sul (BR). Traz contribuições de pesquisadores em educação popular para interpelar os sujeitos (em particular os movimentos sociais populares e as instituições estatais) e discutir a metodologia utilizada neste processo de reformulação curricular. Enfatiza a importância da perspectiva complexa para se compreender os limites e as possibilidades de um processo oficial que pretende promover, paradoxalmente, a inserção dos movimentos sociais alternativos na formulação e no controle das diretrizes curriculares da escola pública.

Between the official and the alternative in curricular proposals: beyond hybridism

The text discusses the relationship between the official and the alternative discourse used in the School Assembly (1999-2000), sponsored by the state government of Rio Grande do Sul, in the south of Brazil. It presents contributions from researchers in the field of Popular Education with the purpose of inciting the subjects (specifically the popular social movements and state institutions) to reflect upon their practices and to discuss the methodology employed in this process of curriculum reform. It also emphasizes the significance of the complex perspective for understanding the limits and possibilities of an official process aimed at promoting, paradoxically, the participation of the alternative social movements in the formulation and control of curricular guidelines for the state school.

Creso Franco

O SAEB - Sistema de Avaliação da Educação Básica: potencialidades, problemas e desafios

Baseado em contribuição preparada no contexto da Comissão de Especialistas, 